\title{
Numerical Analysis of the Moving Formwork Bracket Stress during Construction of a Curved Continuous Box Girder Bridge with Variable Width
}

\author{
Jun Yang ${ }^{1}$, Jianting Zhou ${ }^{1}$, Xiaogang $\mathrm{Li}^{2}$, Aicheng Shan ${ }^{1} \&$ Yang Kuang ${ }^{1}$ \\ ${ }^{1}$ School of Civil Engineering \& Architecture, Chongqing Jiaotong University, Chongqing, China \\ ${ }^{2}$ T.Y.Lin International Engineering (Chongqing) Co., Ltd, Chongqing, China \\ Correspondence: Jun Yang, School of Civil Engineering \& Architecture, Chongqing Jiaotong University, \\ Chongqing 400074, China. E-mail: herohey@163.com
}

Received: December 5, 2014

Accepted: December 12, 2014 Online Published: April 17, 2015

doi:10.5539/mas.v9n6p56

URL: http://dx.doi.org/10.5539/mas.v9n6p56

\begin{abstract}
This paper is based on a curved continuous box girder with variable width. The bracket stress in the process during construction in mobile formwork system is monitored and analyzed. It has elaborated the contents which mobile formwork bracket monitored and methods in the construction of curved continuous box girder with variable width. The bracket stress was analyzed using the numerical analysis method. Accordingly, the theoretical value related to bracket stress is calculated by finite element software-Midas Civil 2010. The model of the combination of transverse and longitudinal shift is put forward, which ensures the security of mobile formwork during construction. A real-time monitoring system is established, and reasonable warning value is set. Furthermore, the data related to bracket stress is measured. Eventually, comparing the values of the field measurement with the one of theoretical calculation, we concluded that the bracket remained safe in the construction process. The analysis of the bracket will afford the experience for the similar bridge constructions and embody preferable practical value.
\end{abstract}

Keywords: variable width, bracket stress, mobile formwork, numerical analysis, transverse and longitudinal shift, warning value, real-time monitoring system

\section{Introduction}

Moving formwork is commonly used in construction of bridge deck equipment, which has strong spanning ability, high degree of automation, short construction period and good comprehensive benefits. Its advantages become more prominent in the valley of the high mountains, considering that the template is made by steel template with large stiffness both inside and outside, and the appearance of the bridge and the lines are easy to guarantee. The phenomenon such as running mode and slurry leakage will not appear. What is more critical is the brackets in the moving formwork system use piers as the support point. In construction process of bridge, it has no specific requirements for the lower space. It's especially suitable for places such as crossroads, channel and tidal flats of bridge construction. The construction does not affect the traffic and has strong environment adaptiveness.

Under normal circumstances, moving formwork is suitable for linear bridge construction. It is rarely used in the practice of curved continuous box girder with variable width bridge. Compared with formwork construction, moving formwork has disadvantages that it is difficultly operated in construction of curved bridge and it required a large investment. In addition, the force of the frame are relatively concentrated, the consequences key parts have caused would be disastrous. Bracket acts as a part of the formwork system, taking all of the loads from the upper structure during the construction. In order to ensure the safety of moving formwork, it's important to monitor the stress of bracket key parts.

In this paper, a curved continuous box girder with variable width bridge is taken as the example. For this system, lateral movement is needed to cross over the span, or guide beam will impact girders. On the basis of this, the combination of transverse and longitudinal shift pattern is put forward. But the trans-verse movement will cause bracket in a state of stress adverse and pose a safety hazard. Therefore, this paper determines the bracket stress monitoring contents and methods, establishes a real-time monitoring system and sets up reasonable warning 
value to ensure the safety during construction. Using Midas finite element calculation software, the calculated values of stress monitoring are analyzed. Through the contrast analysis of the field stress monitoring values and model calculation calculated value, the stress monitoring conclusions are obtained. Analysis of the stress monitoring establishes a kind of efficient, safe and scientific monitoring system, which can provide certain basis for similar bridge construction monitoring and has promotion value and great significance.

\section{Engineering Situation}

A curve widen continuous girder bridge is located in Chongqing. It's the north approach span of a railway cable-stayed bridge. The span arrangement is $3 \times 60+3 \times 60+3 \times 50 \mathrm{~m}$ continuous rigid frame bridge. The first joint box girder adopts single box section, and the second and the third joint single box adopt double chamber section. Piers are hollow rectangular cross section. Span by span method is adopted from abutment. Among them, stents cast-in-place construction method is used in A16 P14 and moving formwork construction method is used in P14 P6. In the process of moving, stress in the key parts of bracket should be monitored. The plan of approach bridge in the North as shown in Figure 1.

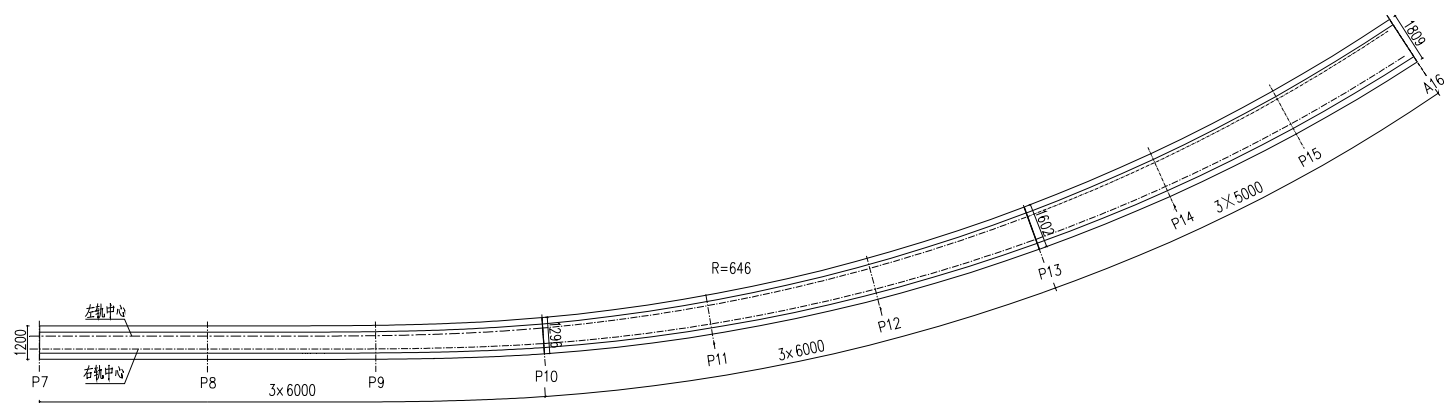

Figure 1. Plan of approach bridge in the North (units: $\mathrm{cm}$ )

\section{Purpose, Method of Stress Monitoring and Arrangement of Measuring Points}

According to the usage of moving formwork in construction, stress of bracket in the process of construction should be monitored.

\subsection{Purpose, Method of Stress Monitoring}

Stress is the key internal indicator to reflect the status of structure and damage. The main purpose of monitoring moving formwork bracket stress is that(to determine the bracket is safe, then guide the construction of formwork moving.) study the internal force distribution of bracket, local structure and connection in response to various loads by monitoring the internal force in control parts and key parts of bracket,.

Stick strain gages in the surface of the steel structure of the stress testing section, strain test by the static strain gauge(DH3815N). Through the measured strain and the elastic modulus of steel can get conversion point stress. Strain test resolution is $1 \times 10-6( \pm 1 \mu \varepsilon)$. Composition of stress and strain data acquisition systems is shown in Figure 2.

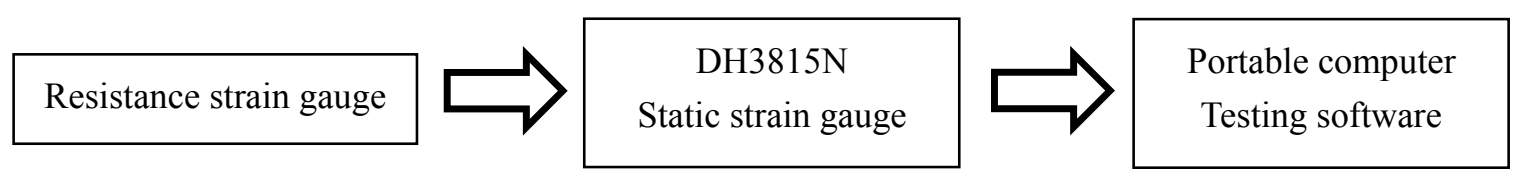

Figure 2. Composition of stress and strain data acquisition system

\subsection{Arrangement of Measuring Points}

In the process of the movement of moving formwork, the bracket stress should be monitored. The arrangement of measuring points as shown in Table 1 . 
Table 1. Stress measuring point arrangement summary

\begin{tabular}{lll}
\hline Test item & Position & Number \\
\hline Bracket brace stress & Top and side in L/2、L/4 span of side brace & 16 \\
Bracket beam stress & Side in L/2、L/4span of beam & 8 \\
Temperature compensation stress & The same material steel & 4 \\
\hline
\end{tabular}

The arrangement of measuring points in the scene is shown in Figure 3.

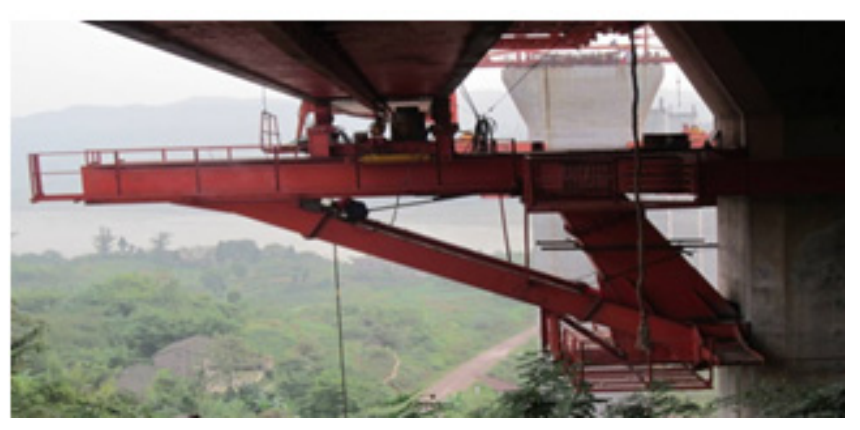

Figure 3. Elevation, measuring point layout of bracket stress

\section{Monitoring Results and Analysis}

\subsection{Calculated FEA Monitoring Stress Calculation}

According to the material parameters of bracket and site construction conditions, we used Midas Civil 2010 finite element software to model and analysis. Bracket is simulated with a total of 42 nodes and 45 units beam elements. Calculated loads and material properties are shown below:

(1) The cast-in-place reinforced concrete density values: $26 \mathrm{kN} / \mathrm{m} 3$;

(2) Steel density values: $7.85 \mathrm{~kg} / \mathrm{m}^{3}$;

(3) Internal formwork + temporary load $=100 \mathrm{t}$, bottom formwork truss $=100 \mathrm{t}$, launching nose $=100 \mathrm{t}$, outer formwork and support $=250 \mathrm{t}$, a plat-form of balancing + ladder platform + part of the hydraulic system + temporary load $=30 \mathrm{t}$, concrete balancer $=120 \mathrm{t}$.

Table 2. Material allowable stress

\begin{tabular}{ccccc}
\hline Steel grade & $\begin{array}{c}\text { thickness } \\
(\mathrm{mm})\end{array}$ & $\begin{array}{c}\text { Axial allowable } \\
\text { stress(MPa) }\end{array}$ & $\begin{array}{c}\text { Shear allowable } \\
\text { stress(MPa) }\end{array}$ & $\begin{array}{c}\text { Face pressure on the } \\
\text { allowable stress(MPa) }\end{array}$ \\
\hline \multirow{3}{*}{ Q345 } & $\leq 16$ & 257 & 149 & 360 \\
& $16 \sim 35$ & 243 & 140 & 340 \\
& $35 \sim 50$ & 235 & 136 & 329 \\
\hline
\end{tabular}

By the model calculation and analysis, the calculated stress value during the process of formwork movement can be calculated. The finite element model structure is as shown in Figure 4. 


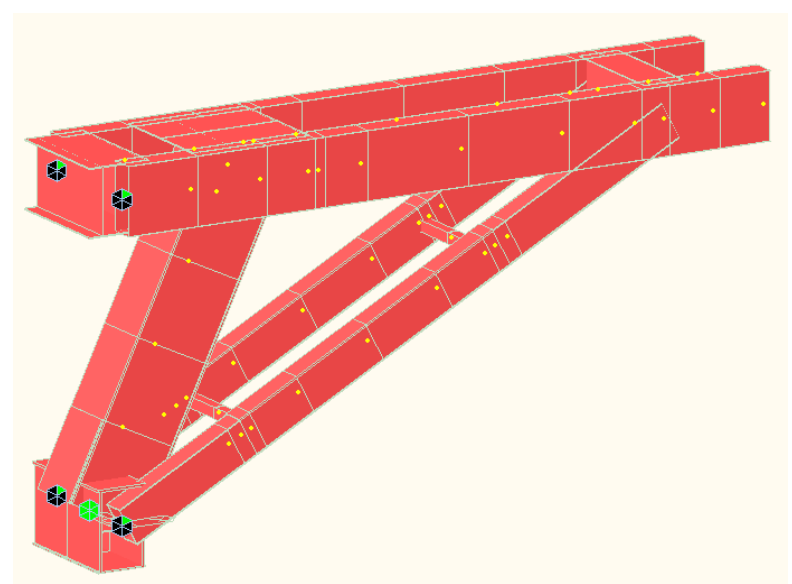

Figure 4. Structure of bracket finite element

\subsection{The Monitoring Process}

According to the situation of field, lateral move to every design position, collect the bracket stress; According to the stress growth situation, collect the bracket stress every $1 \mathrm{~m}$ or $3 \mathrm{~m}$ forward distance. At the beginning, collect the stress at approximate each $1 \mathrm{~m}$ movement. Collect the stress at approximate each $3 \mathrm{~m}$ movement by the code when the stress change stably. Distance will be subject to the actual measurement.

\subsection{The Comparative Analysis of the Calculated and Measured Values}

After using finite element software to calculate the calculated calculation results, we can get the bracket stress measured values according to the content and the method of monitoring. The bracket stress comparative analysis results were illustrated as follows. Because of the large amount of monitoring data, this paper selects the data of moving formwork from the P12 P13 span moved to the P11 P12 span in P12 \# pier upstream side. The comparisons between measured stress value and calculated stress value were shown in Figure $8 \sim 13$. (The compressive stress is negative while the tensile stress is positive.)

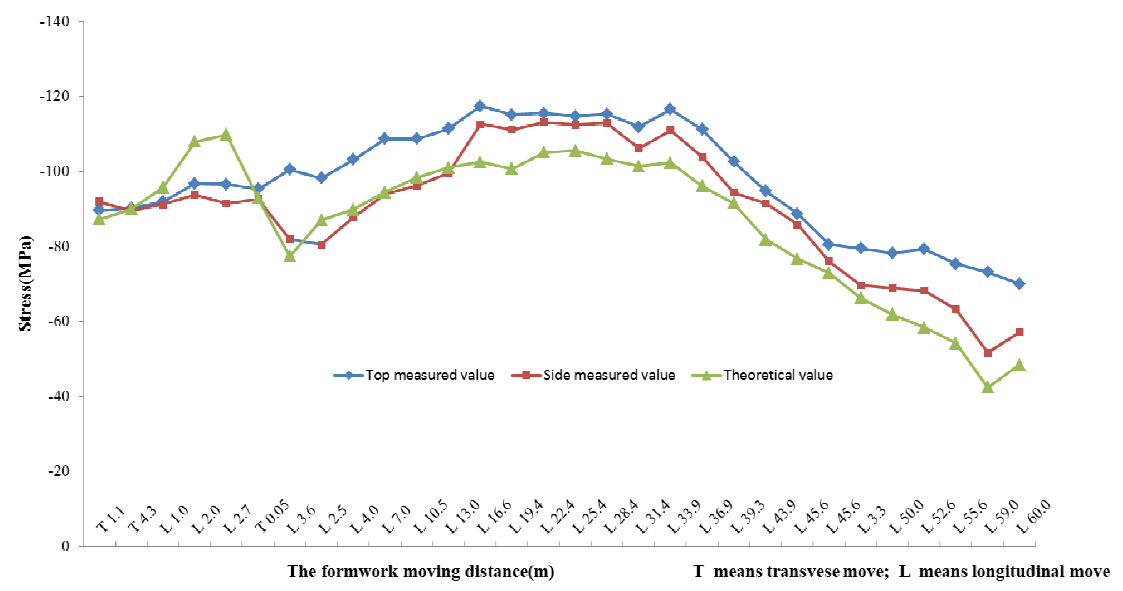

Figure 5. The stress on L / 2 span of side brace in north shore of side bracket in pier 12\# 


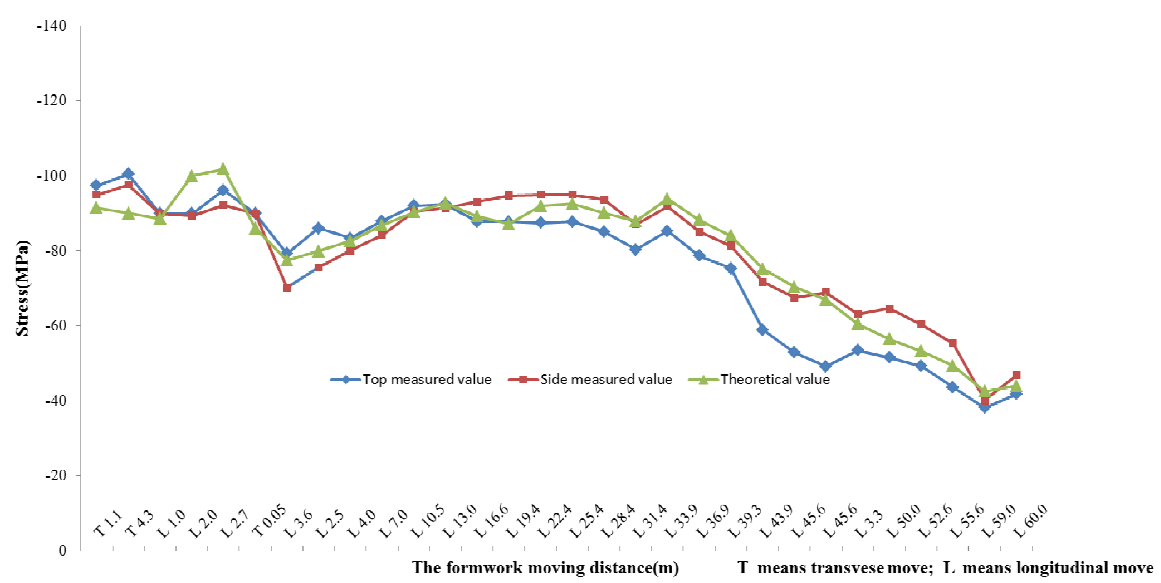

Figure 6. The stress on L / 2 span of side brace in south shore of side bracket in pier 12\#

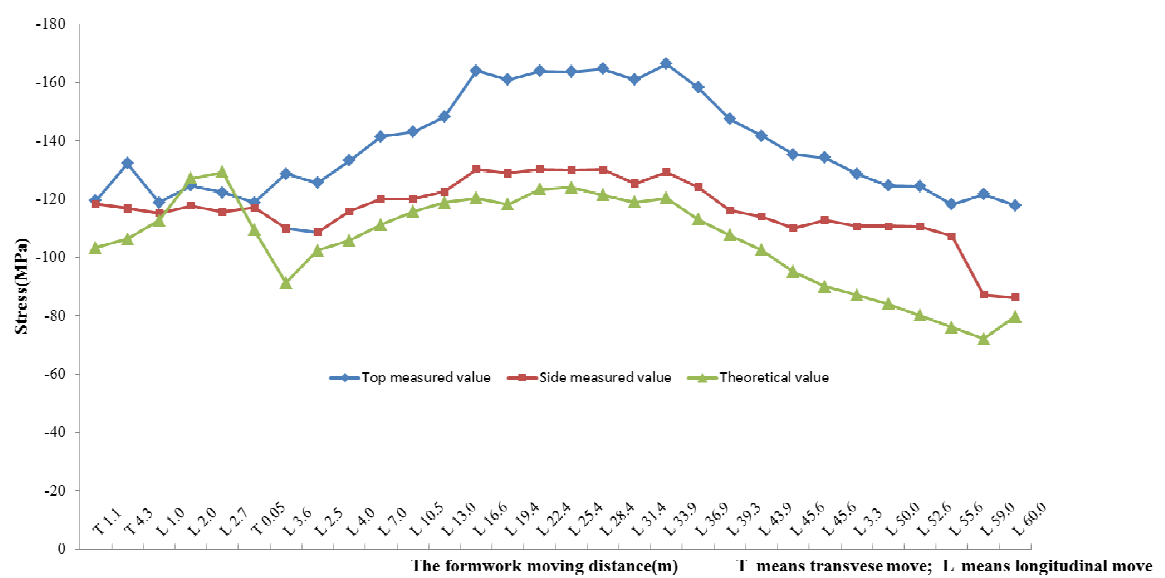

Figure 7. The stress on L / 4 span of side brace in north shore of side bracket in pier 12\#

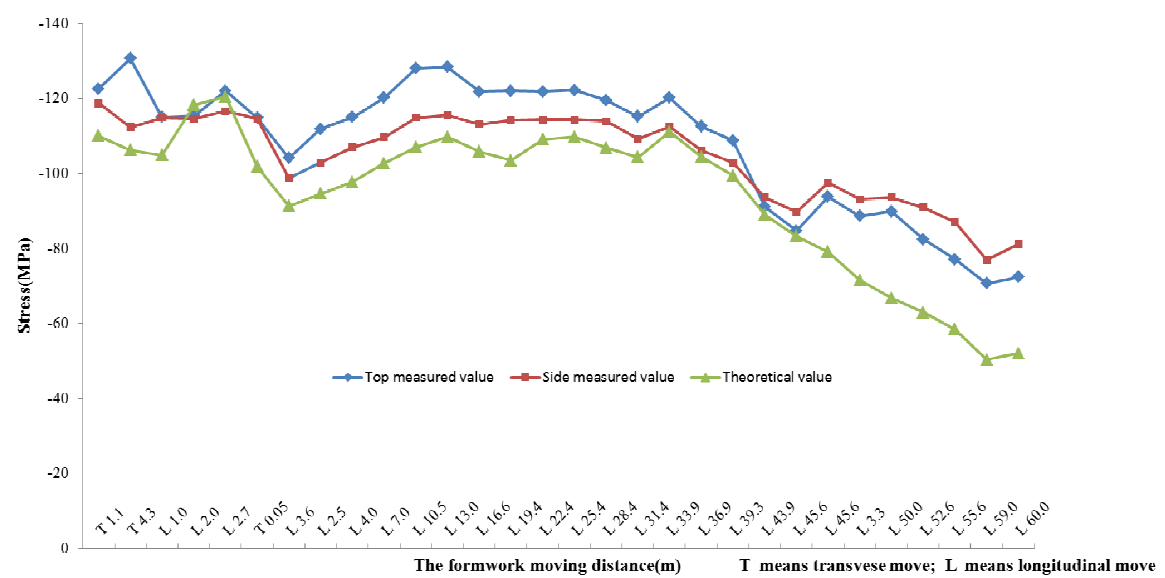

Figure 8. The stress on L / 4 span of side brace in south shore of side bracket in pier 12\# 


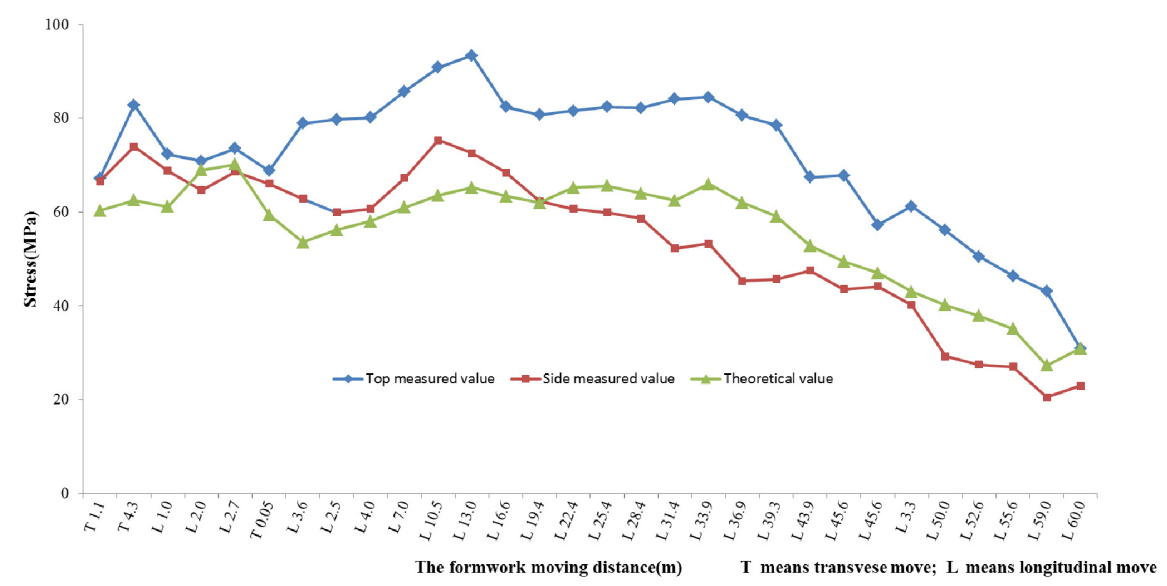

Figure 9. The beam stress on side brace in north shore of side bracket in pier 12\#

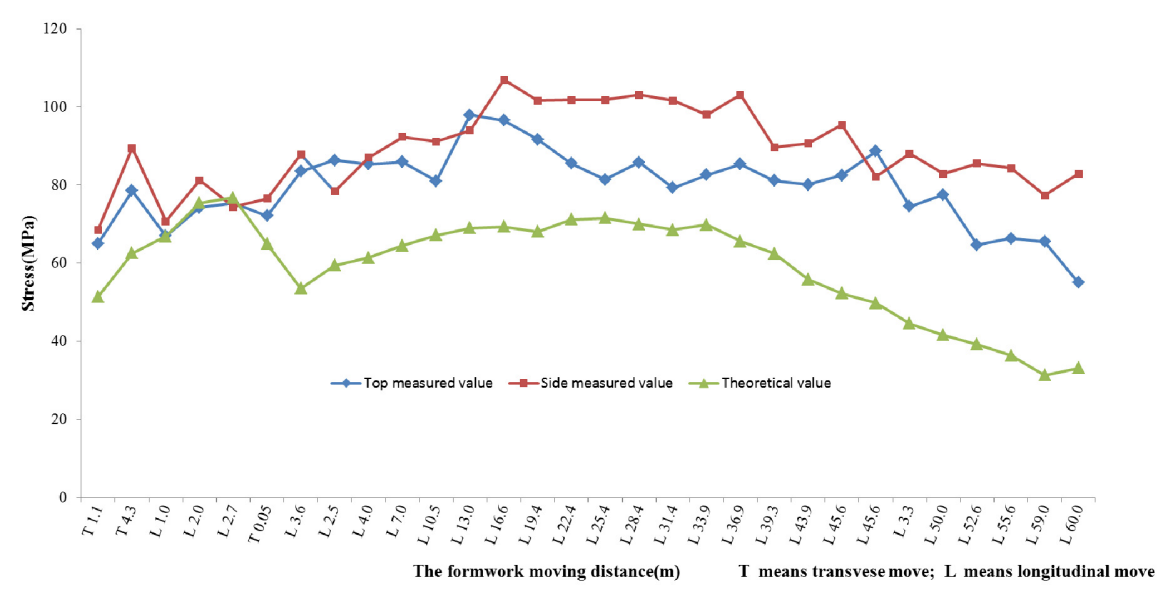

Figure 10. The beam stress on side brace in south shore of side bracket in pier 12\#

We can conclude that, in the process of walking, the maximum compressive stress of formwork appeared on the longitudinal direction forward to $28.4 \mathrm{~m}$. The stress on top L / 4 span of side brace in north shore of side bracket in 12\# pier is $164.65 \mathrm{MPa}$; The maximum tensile stress appeared on the longitudinal forward to $16.6 \mathrm{~m}$. The beam stress on side brace in south shore of side bracket in 12\# pier is $106.96 \mathrm{MPa}$. Most parts of the trend of the measured stress value is roughly same with that of the calculated calculation value, but there exists a certain difference. The reason is that there is a certain difference between simplified simulation of finite element and the actual structure. Besides, the measured values are affected by various causes (such as environmental factors). Analyzed and compared with the table 2, the bracket in the entire process of movement does not exceed the allowable stress values, so the bracket remains in the security state.

Comprehensive analysis of stress monitoring data in each span, indicates that when formwork moves, the bracket produces a stress peak around $50 \%$ of its value in the allowable stress. We should pay close attention to the construction process. Choosing P12, P13 \# pier, in the middle of a curve, and comparing the upstream and downstream side brace stress of $\mathrm{L} / 4$, we found that the upstream side stress significantly higher than that of the downstream side. The reason is that upstream side is located in the outside of curve, and bracket support point is far away from the root, which generates great compressive stress. Therefore, we should pay attention to the lateral brackets stress value in the curve of the lateral. In addition, with formwork moving forward, the possibility of guide beam in the inside of the curve impacts the bridge beam body has increased. Although the bracket stress is small, we should focus on the distance between the front guide beam and the main girder. According to the actual situation, the real-time transverse formwork, reserve more than $50 \mathrm{~cm}$ to prevent guide beam and the bridge beam body collision.

Steel structure design use allowable stress method and strength design in order to control the stress shall not exceed the material allowable stress. We introduce the stress warning value in the process of monitoring, its value calculation is elaborated as follows: 


$$
P_{w}=\zeta \times P_{a}
$$

$P_{w}$ is Warning value; $\zeta$ is safety factor; $P_{a}$ is allowable stress

In the formula, the safety factors are $0.7,0.8$ and 0.9 , Real-time acquisition of stress analysis in the process of monitoring to determine the safety status of bracket. The stress warning decision is shown in Table 3.

Table 3. Stress warning decision

\begin{tabular}{cc}
\hline Warning value(MPa) & warning decision \\
\hline 164.5 & Safety, move according to the design \\
188 & Safety, need to see the stress growth trend \\
211.5 & Stop, identify the cause of excessive stress \\
\hline
\end{tabular}

Choose representative working condition to test the warning decision, as shown in Table 4.

Table 4. Representative condition warning decision

\begin{tabular}{|c|c|c|c|c|}
\hline $\begin{array}{l}\text { Testing working } \\
\text { condition }\end{array}$ & Testing position & $\begin{array}{l}\text { Measured value } \\
(\mathrm{MPa})\end{array}$ & $\begin{array}{l}\text { Warning value } \\
(\mathrm{MPa})\end{array}$ & $\begin{array}{l}\text { Warning } \\
\text { decision }\end{array}$ \\
\hline $\begin{array}{c}\text { The longitudinal forward } \\
\text { to } 28.4 \mathrm{~m}\end{array}$ & $\begin{array}{l}\text { Top L/4 span of side } \\
\text { brace in north shore } \\
\text { of side bracket in } \\
12 \# \text { pier }\end{array}$ & 164.65 & 188 & safety \\
\hline $\begin{array}{c}\text { The longitudinal forward } \\
\text { to } 16.6 \mathrm{~m}\end{array}$ & $\begin{array}{l}\text { Beam side brace in } \\
\text { south shore of side } \\
\text { bracket in } 12 \# \text { pier }\end{array}$ & 106.96 & 164.5 & safety \\
\hline
\end{tabular}

In conventional methods of passing hole, there are dangers such as guide beam hitting the main girder and the big bracket stress. The moving process, which was repeatedly calculated, can be safely and efficiently applied to pass hole.

\section{Conclusion}

During monitoring process, to meet the requirement of stiffness, strength and stability should do the static calculation. Then, in process of moving to monitor the stress, displacement and other indicators is more appropriate. This paper clarified the whole procedure of setting the stress and strain data acquisition system in the key position in mobile formwork bracket and using the system to monitor the safety of $60 \mathrm{~m}$ curved continuous box girder with variable during the process of passing the hole. We formulate the control indicators of moving formwork and use these safety indicators to alarm in time. Furthermore, we reduce the structure stress level in time and illustrate the use of the monitoring method which can effectively control the safety during construction process, based on real time control of the monitoring information. Analyzing the measured values and calculating values by the finite element software, we can draw conclusions:

(1) Determine the reasonable passing hole pattern of curved continuous box girder with variable width after repeated calculation, including the amount of transverse, longitudinal shift, which reduces the bracket stress;

(2) Set up a feasible real-time monitoring system to continuously monitor, and simultaneously control the stress of the bracket, which can determine the safety of the bracket;

(3) Set up a reasonable warning system. The measured maximum value is $164.65 \mathrm{Mpa}$, more than the calculated calculation value, but in the safety range. Although the measured value with the calculated value in numerical has certain gap, the measured stress value always does not exceed the value of warning, which can be judged bracket in a safe state in the process of construction;

(4) The calculated calculation values get feedback from the measured data. The future engineering practice provides an economical and reliable, safe and practical passing holes pattern. 


\section{References}

Chen, Z., Zhang, C., \& Zhou, J. et al. (2013) Study of Cable Force of Construction Control and Alignment Control of Main Girders for Long-Span Railway Cable-Stayed Bridges. Modern Applied Science, 7(9), 47. http://dx.doi.org/10.5539/mas.v7n9p47

Haiqing, L., \& Yang, W. (2007). Bridge pier defor-mation and bearing capacity analysis during mobile formwork construction. Highway, 4, 68-70.

Jiang, K. B., \& Zhou, W. J. (2005). Cause and coun-termeasure of slab cracks of pre-stressed concrete continuous box girder. Journal of PLA University of Science and Technology, 6(4), 369-373.

Jun, C., Cheng, Z., Zengshun, C., \& Jun, Y. (2014). Analysis and Research on Deformation Monitoring of Large Span Cable-stayed Bridge during Operating Period. Modern Applied Science, 8(3).

Liu, J. F., \& Ye, J. (2009). Method for the Bridge Construction of Chinese Passenger Dedicated Lines with Mobile Mould. Railway Standard Design, 30(1), 54-60.

Zengshun, C., Jun, S., \& Cheng, Z. et al. (2013). Study of Different Construction Processes Affecting the Installation of Appropriate Cambers for Long-Span Railway Cable-Stayed Bridges. Modern Applied Science, 7(8). http://dx.doi.org/10.5539/mas.v7n8p89

Zhao, Q. L., Pu, W., \& Chen, Y. F. (2005). Safety moni-toring and control of movable supporting mold based on optical fiber monitoring system. Journal of PLA University of Science and Technology, 6(5), 469-473.

Zheng, Z. L., Shen, B. C., Zhang, P., \& Lu, P. M. (2007). Study on the Stress Law for the Leading Beam of Large-scale Bridge Building Ma-chine during the Lengthways Moving Course. Bridge Machinery \& Construction Technology, 4, 38-39.

\section{Copyrights}

Copyright for this article is retained by the author(s), with first publication rights granted to the journal.

This is an open-access article distributed under the terms and conditions of the Creative Commons Attribution license (http://creativecommons.org/licenses/by/3.0/). 